\title{
A Sporolactobacillus-, Clostridium-, and Paenibacillus- Dominant Microbial Consortium Improved Anaerobic RDX Detoxification by Starch Addition
}

\author{
Muhammad Imran Khan ${ }^{1,2,4}$, Keunje Yoo ${ }^{1,5}$, Seonghoon Kim ${ }^{1}$, Sardar Alam Cheema ${ }^{3}$, \\ Safdar Bashir ${ }^{2}$, and Joonhong Park ${ }^{1 *}$
}

${ }^{1}$ Department of Civil and Environmental Engineering, College of Engineering, Yonsei University, Seoul 03722, Republic of Korea

${ }^{2}$ Institute of Soil and Environmental Sciences, University of Agriculture, Faisalabad 38040, Pakistan

${ }^{3}$ Department of Agronomy, University of Agriculture, Faisalabad 38040, Pakistan

${ }^{4}$ Department of Isotope Biogeochemistry, Helmholtz Centre for Environmental Research-UFZ, 04318 Leipzig, Germany ${ }^{5}$ Department of Environmental Engineering, College of Engineering, Korea Maritime and Ocean University, Busan 49112, Republic of Korea

In the present study, an anaerobic microbial consortium for the degradation of hexahydro-1,3,5trinitro-1,3,5-triazine (RDX) was selectively enriched with the co-addition of RDX and starch under nitrogen-deficient conditions. Microbial growth and anaerobic RDX biodegradation were effectively enhanced by the co-addition of RDX and starch, which resulted in increased RDX biotransformation to nitroso derivatives at a greater specific degradation rate than those for previously reported anaerobic RDX-degrading bacteria (isolates). The accumulation of the most toxic RDX degradation intermediate (MNX [hexahydro-1-nitroso-3,5-dinitro-1,3,5-triazine]) was significantly reduced by starch addition, suggesting improved RDX detoxification by the co-addition of RDX and starch. The subsequent MiSeq sequencing that targeted the bacterial 16S rRNA gene revealed that the Sporolactobacillus, Clostridium, and Paenibacillus populations were involved in the enhanced anaerobic RDX degradation. These results suggest that these three bacterial populations are important for anaerobic RDX degradation and detoxification. The findings from this work imply that the Sporolactobacillus, Clostridium, and Paenibacillus dominant microbial consortium may be valuable for the development of bioremediation resources for RDX-contaminated environments.

Keywords: Bioremediation, explosives, MiSeq, starch, Sporlactobacillus

Received: October 16, 2019 Accepted: March 5, 2020

First published online: March 9, 2020

${ }^{*}$ Corresponding author Phone: $+82-2-2123-7768$ Fax: +82-2-312-5798 E-mail: parkj@yonsei.ac.kr

Supplementary data for this paper are available on-line only at http://jmb.or.kr.

pISSN 1017-7825 elSSN $1738-8872$

Copyright(C) 2020 by The Korean Society for Microbiology and Biotechnology

\section{Introduction}

Hexahydro-1,3,5-trinitro-1,3,5-triazine (RDX) is one of the most commonly used explosives in the world [1]. The global manufacturing, storage, detonation, and disposal of this explosive compound have caused widespread contamination of soil [2,3]. RDX migrates through soil and potentially causes groundwater contamination [4-6] owing to its weak sorption affinity for soil and fairly high solubility in water $\left(60 \mathrm{mg} \mathrm{l}^{-1}\right.$ at $\left.20^{\circ} \mathrm{C}\right)$ [7]. RDX is classified as a class $\mathrm{C}$ carcinogen, and it exhibits toxic properties to organisms even at low concentrations $[8,9]$. Because of the high degree of pollution exposure and toxicity of RDX, the removal of RDX from polluted environments is of vital importance for the protection of human health and ecological systems against explosive contamination.

Microorganisms have been shown to be able to biodegrade RDX under aerobic and anaerobic conditions via different degradation pathways [10-11]. Under aerobic conditions, one nitro group of the RDX is removed (via denitration-hydration step) before the destabilization and cleavage of ring, resulting in the formation of 4-nitro2,4-diazabutanal (NDAB) or methylenedinitramine (MEDINA), formaldehyde, and carbon dioxide [10, 11]. Under anaerobic conditions, RDX is degraded via sequential nitro-reduction to produce hexahydro-1-nitroso3,5-dinitro-1,3,5-triazine (MNX), hexahydro-1,3-dinitroso-5-nitro-1,3,5-triazine (DNX) and hexahydro-1,3,5trinitroso-1,3,5-triazine (TNX) before ring cleavage. The MNX may further denitrosate or denitrate and after ring cleavage produce MEDINA or NDAB [or 4-nitoso-2,4-diazabutanal (NO-NDAB)]. The direct ring cleavage of RDX produces MEDINA and bis(hydroxymethyl)nitramine (BHNA), followed by formation of nitrous oxide and formaldehyde as end products $[10,11]$ 
Although aerobic microbial degradation of RDX has recently been regarded as a promising biological process to clean up explosive-contaminated sites [10-18], the use of aerobic RDX degradation in contaminated sites might be limited because of a low saturation level of dissolved oxygen (DO) and the cost-ineffective means of supplying DO $[8,11]$, particularly in subsurface environments. When DO supply is limited, anaerobic microbial degradation of RDX is regarded as a feasible biological alternative for bioremediation of explosive-contaminated sites $[8,11,20,21]$.

For anaerobic degradation of RDX, an external carbon source is often added to provide enhanced reducing conditions [4] or to stimulate the RDX degradation and growth of anaerobic RDX-degrading microbes [22-26]. In the case of bacterial isolates, simple carbon sources such as glucose [24,27], acetate [28,29], succinate [30] and ethanol $[23,28]$ have been typically used for stimulation of microbial degradation of RDX. However, for mixed culture conditions or consortia, the use of simple sources of carbon may not work well because simple carbon sources may be preferentially used by fast-growing non-degradative bacteria instead of relatively slow-growing RDX-degrading bacteria [31,32]. To circumvent this problem, slow-releasing sources of carbon such as starch and molasses have often been used to maintain a high degree of degradative activity and population diversity in microbial mixed-culture or community conditions [4,33,34].

Starch is an effective stimulant for enriching RDX-degrading consortia because of its widespread availability, cost-effectiveness, easy biodegradability, and complex nature [28]. Our previous study revealed that co-addition of RDX and starch could enhance RDX degradation and detoxification under aerobic conditions [34], and the 16S rRNA gene amplicon pyrosequencing identified the involvement of a Rhizobium population in the enhanced aerobic RDX degradation and detoxification by starch addition. However, the effects of starch addition on anaerobic RDX degradation/detoxification and population dynamics have yet to be examined.

In this work, starch was used in the selective cultivation of a novel anaerobic microbial consortium capable of RDX detoxification. The specific research objectives were (i) to study the impacts of starch addition on the formation of intermediates and specific biodegradation rates of anaerobic RDX degradation under no fixednitrogen conditions and (ii) to explore its effects on the bacterial communities and identify bacterial populations related to anaerobic RDX detoxification.

\section{Materials and Methods}

\section{Chemicals}

RDX (purity > 99\%) was obtained from AccuStandard, Inc. (USA). HPLC-grade methanol, isopropyl alcohol, acetone, and acetonitrile were obtained from J. T. Baker (USA). Starch (soluble) was obtained from Junsei Chemicals Co. Ltd. (Japan). Water, used for the HPLC mobile phase and the aqueous growth medium, was purified using a Compact Ultrapure Water System and an EASYpure Reverse Osmosis System obtained from Barnstead/Thermolyne (USA).

\section{Microcosm Experiments}

Anaerobic incubation experiments were carried out using 160-ml glass serum bottles containing $150 \mathrm{ml}$ of aqueous growth medium. The growth medium was comprised of as follows (in grams per liter): $\mathrm{KCl}(0.1)$, $\mathrm{NaH}_{2} \mathrm{PO}_{4} \cdot \mathrm{H}_{2} \mathrm{O}(0.6), \mathrm{NaHCO}_{3}(2.5), 0.5 \mathrm{ml}$ of $1 \mathrm{mM} \mathrm{Na}_{2} \mathrm{SeO}_{4}$, and modified Wolfe's mineral and vitamin mixtures (each $10 \mathrm{ml}$ per liter) [35]. Starch (at different concentrations, i.e. $0,2.5$, and $5.0 \mathrm{~g} \mathrm{l}^{-1}$ ) was added as a slow-releasing external source of carbon in this study. After $1 \mathrm{~h}$ of flushing with oxygen-free nitrogen gas, microcosm bottles were sealed and autoclaved $\left(45 \mathrm{~min}\right.$ at $\left.121^{\circ} \mathrm{C}\right)$. RDX was added to the microcosm bottles using acetone as a carrier solvent and bottles were shaken to dissolve RDX in liquid growth medium. To evaporate the acetone, bottles were placed in an anoxic chamber (Coy Laboratory Products Inc., USA) for $8 \mathrm{~h}$. Approximately $10 \mathrm{ml}$ of liquid medium was removed from the prepared bottle and was added into a clean sterile falcon tube carrying $5 \mathrm{~g}$ of soil collected from a military shooting site at Darokdae (Korea).

Falcon tubes were shaken and swirled for the extraction of inoculum. Extractants (carrying inocula) were added back to the representing bottle, after settling larger soil particles. Sterile controls were also prepared to assess abiotic abasement of RDX. In the control microcosm, bottles were autoclaved again after addition of inocula, and finally RDX was added in the autoclaved bottles. Microcosm bottles were completely wrapped with aluminum foil to avoid photo-degradation of RDX [36]. The final $\mathrm{pH}$ was $7.1 \pm 0.2$. The details of different treatments used in first and each subsequent sub-culture experiment are provided in Table $S 1$, and all experiments were done in triplicate. The microcosm bottles were incubated at $25.0 \pm 0.5^{\circ} \mathrm{C}$ in the dark without shaking. Periodic samples were taken for analysis using disposable syringes and 21-gauge needles.

After the $1^{\text {st }}$ enrichment experiment, a subculture experiment (i.e., $2^{\text {nd }}$ enrichment) was conducted to affirm the degradative potential of growing culture and screen RDX-degrading consortia. Approximately $15.0 \mathrm{ml}$ of grown culture from the 1st enrichment was transferred to $135 \mathrm{ml}$ of freshly prepared sterile anoxic liquid growth medium containing RDX using disposable syringes and 21 -gauge needles, and the resultant microcosm was named the $2^{\text {nd }}$ enrichment. Similarly, $150 \mathrm{ml}$ of $3^{\text {rd }}$ enrichment microcosm was prepared by receiving $15.0 \mathrm{ml}$ of culture from the $2^{\text {nd }}$ enrichment. All microcosms were incubated without shaking at $25.0 \pm 0.5^{\circ} \mathrm{C}$ in the dark, and they were sampled periodically to monitor RDX degradation and microbial growth. Among each three replicates, the one with the best biodegradation was chosen for further transfer and estimation of biodegradation rates. 
Specific Rates of RDX Degradation

Specific biodegradation rates $(\mathrm{R})$ of RDX were calculated using the following equation:

$$
\mathrm{R}=\frac{\left(C_{n}-C_{n-1}\right)}{\left(t_{n}-t_{n-1}\right)} \times \frac{1}{O D_{a v}}
$$

where $t_{n}$ and $t_{n-1}$ represent two continuous sampling times, $C_{n}$ and $C_{n-1}$ represent the concentrations of RDX in the microcosms at the matching sampling times, and $O D_{a v}$ represents the average OD values between $t_{n}$ and $t_{n-1}$.

\section{Analytical Methods}

RDX and its biotransformation intermediates, such as MNX, DNX, and TNX, were analyzed using HPLC (Agilent Technologies 1200 series, USA) at $230 \mathrm{~nm}$ following the EPA Method 8330 [37, 38] with slight modifications as described in Khan et al. [34]. For quantification of microbial growth, optical density (OD) at $600 \mathrm{~nm}$ was measured using a spectrophotometer (UV/VIS) (Mecasys Co. Ltd., Korea).

\section{Statistical Anaylses}

Data were analyzed using the SPSS statistical package, version 16.0 (SPSS Inc., Chicago, IL) for Windows [39]. ANOVA was applied to find differences between different treatments and controls $(p<0.05)$.

\section{DNA Extraction, PCR Amplification, MiSeq Sequencing}

Extraction of total genomic DNA from the soil sample (initially used for the $1^{\text {st }}$ enrichment) and from selected microcosms (amended with different concentrations of starch) of $3^{\text {rd }}$ enrichment (after 26 days of incubation) was done using a Soil DNA Extraction Kit (MOBIO, CA) following the manufacturer's guidelines. Bacterial 16S rRNA genes were PCR amplified and V3 and V4 regions were targeted using the forward primer (5'-TCGTCGGCAGCGTCAGATGT-GTATAAGAGACAGCCTACGGGNGGCWGCAG-3') and reverse primer (5'-GTCTCGTGGGCTCGGAGATGTGTATAAGAGACAGGACTACHVGGGTA-TCTAATCC-3') [40]. Each PCR reaction (for a total volume of $25 \mu \mathrm{l}$ ) contained $2.5 \mu \mathrm{l}$ of microbial DNA $(5 \mathrm{ng} / \mu \mathrm{l}), 12.5 \mu \mathrm{l}$ of $2 \mathrm{x}$ KAPA HiFi HotStart ReadyMix, and $5 \mu$ of each primer $(1 \mu \mathrm{M})$. Amplification occurred in a GeneAmp PCR System 9600 Thermal Cycler (Applied Biosystems, USA) and amplification conditions are: an initial denaturation step at $94^{\circ} \mathrm{C}$ for $3 \mathrm{~min}$, followed by 25 cycles of denaturation at $95^{\circ} \mathrm{C}$ for $30 \mathrm{sec}$, annealing at $55^{\circ} \mathrm{C}$ for $30 \mathrm{sec}$, and extension phase at $72^{\circ} \mathrm{C}$ for $30 \mathrm{sec}$, and subsequently followed by a final extension at $72^{\circ} \mathrm{C}$ for $5 \mathrm{~min}$. The PCR purification was performed using the MinElute PCR Purification Kit (Qiagen, USA) [41]. Amplicon sequencing was conducted by Macrogen (Korea) on the Illumina MiSeq platform. Analysis of sequences was carried out according to the protocol suggested by Kozich et al. [42] using Mothur (v. 1.31). A phylogenetic tree analysis was conducted for comparison of the sequences (obtained in this study) with the 16S rRNA gene sequences existing in the GenBank through BLAST: http://www.ncbi.nlm.nih.gov/BLAST/. The MUSCLE was used for sequence alignment [43], and MEGA $\mathrm{X}$ software program was used to build a phylogenetic tree following the method described by Khan et al. [34]. The representative nucleotide sequences obtained in this study were deposited in the GenBank under the accession numbers KR779830- KR779845.

\section{Results}

\section{Impact of Starch Addition on Anaerobic RDX Degradation}

Significant disappearance of RDX was observed in the live microcosms (solid line) compared with the abiotic losses detected in the autoclaved control experiments (dashed line) (Fig. 1A). Interestingly, a significant amount of RDX was degraded in the live microcosms in the absence of starch (blank circle). The co-addition of starch with
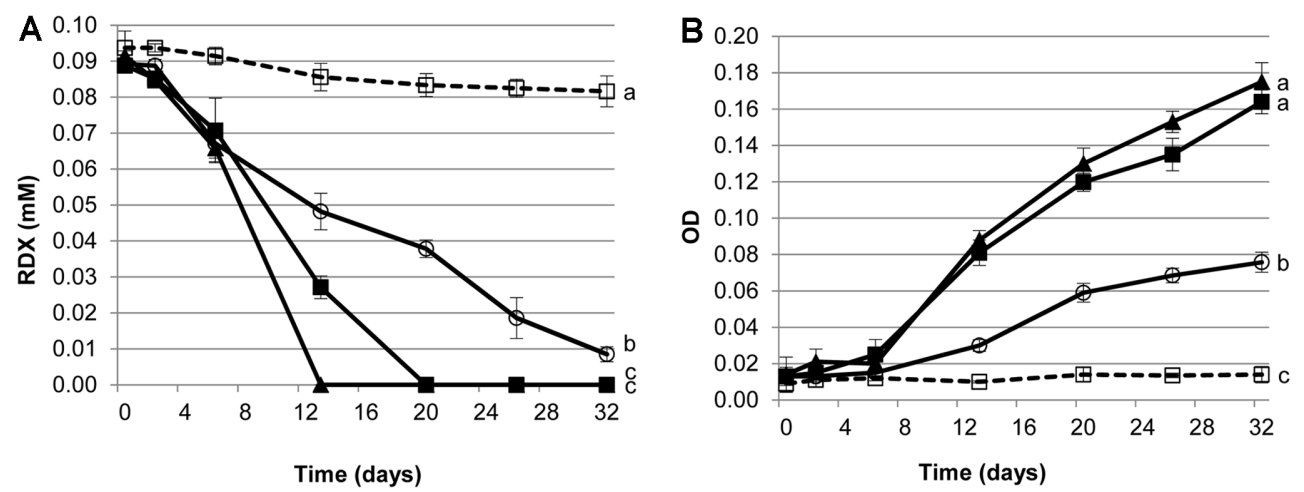

Fig. 1. Anaerobic biodegradation of RDX (A) and microbial growth (B) in the 3rd (last) enrichment experiment. The symbols indicate autoclaved control microcosm with RDX in the absence of starch (-- $\square--)$, microcosm with RDX in the absence of starch (- - -), microcosm with RDX in the presence of $2.5 \mathrm{~g} / \mathrm{L}$ of starch (- $\mathbf{\Delta}$-), and microcosm with RDX in the presence of $5.0 \mathrm{~g} / \mathrm{l}$ of starch (- -). Each error bar represents one standard deviation of three replicates. Variants with the same lower-case letter are not significantly different at $p<0.05$. (OD, optical density at $600 \mathrm{~nm}$ ). 


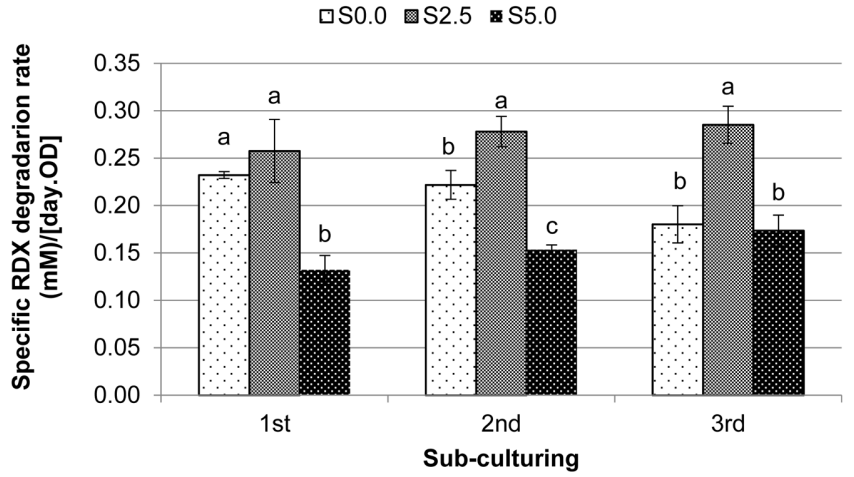

Fig. 2. Specific rates of anaerobic RDX degradation in response to sub-culturing and starch addition. $S O . O$ indicates the microcosm with RDX in the absence of starch, $S 2.5$ is the microcosm with RDX in the presence of $2.5 \mathrm{~g} / \mathrm{l}$ of starch, and $S 5.0$ is the microcosm with RDX in the presence of $5.0 \mathrm{~g} / \mathrm{l}$ of starch. Variants with the same lower-case letter are not significantly different at $p<0.05$. Each error bar represents one standard deviation of three replicates.

RDX enhanced the growth-associated biodegradation of RDX vs. that for the no-starch RDX-induced consortium (S0.0) (Fig. 1). When $2.5 \mathrm{~g} / \mathrm{l}$ of starch was amended, the greatest specific rate of RDX biodegradation was observed among the tested microcosms; a higher starch concentration $(5.0 \mathrm{~g} / \mathrm{l})$ resulted in a reduced specific degradation rate (Fig. 2). In the following $2^{\text {nd }}$ and $3^{\text {rd }}$ sub-culture experiments, specific RDX biodegradation rates for $\mathrm{S} 2.5$ and S5.0 were further increased ( $p<0.147$ for S2.5 and $p<0.061$ for S5.0). In the no-starch RDX-induced microcosms (S0.0), however, the specific rate of RDX biodegradation further decreased in the subsequent sub-culturing experiments $(p<0.037)$, indicating an increased loss of RDX degradation activity in the no-starch and RDXinduced consortium during the sub-culturing. This might be due to the loss of active biomass resulting from subculturing. The anaerobic RDX-degrading microbial consortium obtained from the $3^{\text {rd }}$ (the final) sub-culture experiments was named IK. Specific rates of anaerobic RDX degradation by the IK consortium in the presence (S2.5) and absence of starch (S0.0) were greater $(p<0.01)$ than those for most of the known anaerobic RDXdegrading bacteria (Table 1).

Table 1. Comparison of anaerobic RDX biodegradation rates between the known RDX-degrading isolates and IK consortium from this work.

\begin{tabular}{|c|c|c|c|c|c|}
\hline Microbial isolates/consortia & Carbon substrate $(\mathrm{g} / \mathrm{l})$ & $\begin{array}{c}\text { RDX } \\
(\mathrm{mM})\end{array}$ & $\begin{array}{c}\text { Degradation } \\
\text { rate } \\
(\mathrm{mM} / \text { day })\end{array}$ & $\begin{array}{c}\text { Specific } \\
\text { degradation } \\
\text { rate } \\
{[(\mathrm{mM}) /} \\
(\text { day.OD })]^{1}\end{array}$ & References \\
\hline $\begin{array}{l}\text { Acetobacterium malicum } \\
\text { strain HAAP-1 }\end{array}$ & NA & 0.029 & 0.002 & $N A$ & {$[45]$} \\
\hline Anaerovibrio lipolyticus & Acetate $(4.1)+$ butyrate $(1.8)+$ citrate $(1.1)$ & 0.059 & 0.012 & NA & {$[29]$} \\
\hline Citrobacter freundii & Citrate $(0.06)$ & $N A$ & 0.007 & $0.003-0.005$ & {$[24]$} \\
\hline $\begin{array}{l}\text { Clostridium bifermentans } \\
\text { HAW-1 }\end{array}$ & $N A$ & 0.104 & 0.032 & $0.154-0.172$ & {$[44]$} \\
\hline $\begin{array}{l}\text { Clostridium } \\
\text { polysaccharolyticum }\end{array}$ & Acetate $(4.1)+$ butyrate $(1.8)+$ citrate $(1.1)$ & 0.074 & 0.014 & $N A$ & [29] \\
\hline Clostridium sp. strain EDB2 & Glucose (4.5) + lactate (2.25) & 0.020 & 0.010 & $0.018-0.022$ & {$[27]$} \\
\hline Desulfovibrio desulfuricans & Acetate $(4.1)+$ butyrate $(1.8)+$ citrate $(1.1)$ & 0.008 & 0.002 & $N A$ & {$[29]$} \\
\hline $\begin{array}{l}\text { Klebsiella pneumoniae strain } \\
\text { SCZ-1 }\end{array}$ & Glucose (1.0) & $N A$ & 0.009 & $0.010-0.014$ & {$[24]$} \\
\hline Prevotella ruminicola & Acetate $(4.1)+$ butyrate $(1.8)+$ citrate $(1.1)$ & 0.032 & 0.006 & $N A$ & {$[29]$} \\
\hline Pseudomonas fluorescens I-C & Succinate $(0.73)$ & 0.016 & 0.001 & $N A$ & {$[30]$} \\
\hline Pseudomonas putida II-B & Succinate $(0.73)$ & 0.011 & 0.004 & $N A$ & {$[30]$} \\
\hline $\begin{array}{l}\text { Shewanella halifaxensis } \\
\text { HAW-EB4 }\end{array}$ & $N A$ & 0.090 & 0.004 & $0.001-0.002$ & {$[46]$} \\
\hline IK consortium & Starch (2.5) & 0.092 & 0.015 & $0.670-0.830$ & This study \\
\hline IK consortium & Starch $(0.0)$ & 0.022 & 0.004 & $0.210-0.275$ & This study \\
\hline
\end{tabular}

NA: not available

${ }^{1}$ Values are estimated using the amounts of degraded RDX over a specific time period and the final OD (optical density) value of microbial growth and these values were obtained using a general calculation formula by assuming that all OD values were obtained at the same wavelength. 


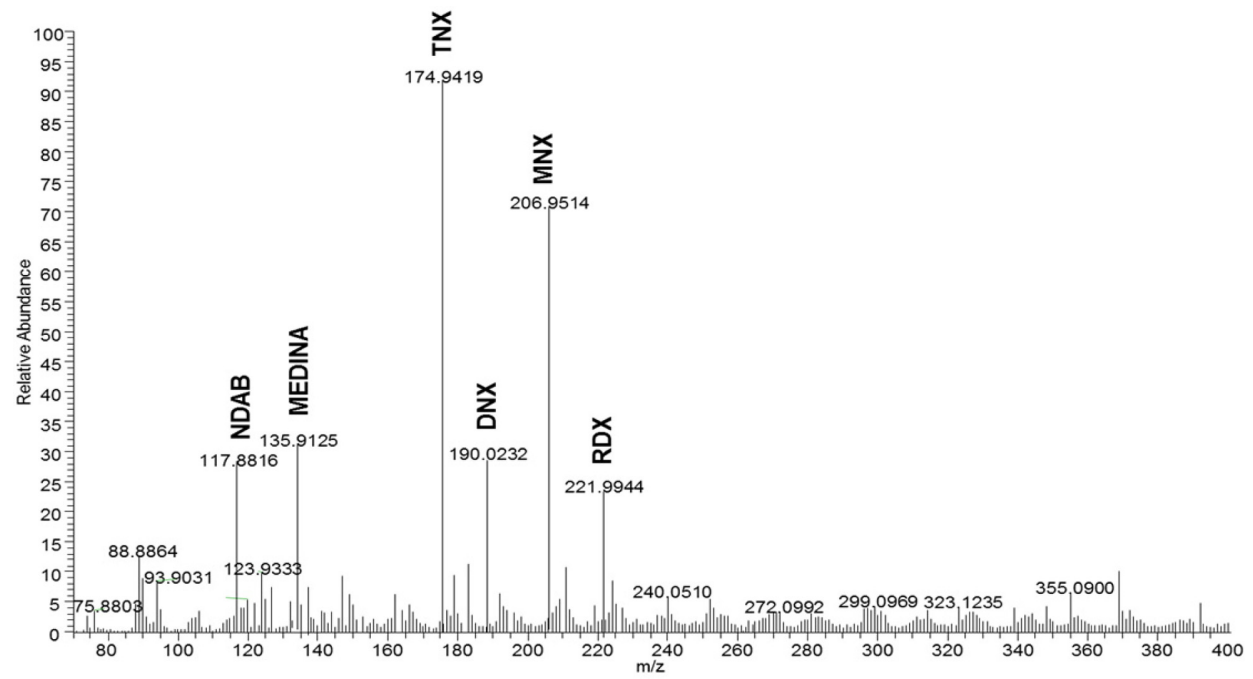

Fig. 3. Mass spectra (LC/MS) of the metabolites formed during microbial degradation of RDX. The MNX, DNX, TNX, MEDINA, and NDAB indicate hexahydro-1-nitroso-3,5-dinitro-1,3,5-triazine, hexahydro-1,3-dinitroso-5-nitro1,3,5-triazine, hexahydro-1,3,5-trinitroso-1,3,5-triazine, methylenedenitramine, and 4-nitro-2,4-diazabutanal respectively.

\section{Impact of Starch Addition on Degradation Intermediates}

Through sequential nitro-reduction, anaerobic microbial degradation of RDX produces MNX, DNX and TNX before ring cleavage; however, the direct ring cleavage of RDX yields MEDINA and BHNA as degradation intermediates [10]. Moreover, the ring cleavage of MNX may further denitrosate or denitrate to produce MEDINA or NDAB (or even NO-NDAB), respectively [11]. In the present study, the HPLC analysis showed the formation of MNX, DNX, and TNX as the main RDX degradation intermediates in anaerobic RDX-degrading microcosms (Fig. S1). Furthermore, chromatograms of HPLC demonstrated the production of an unknown metabolite (Fig. S1), which was identified as more likely to be MEDINA and/or less likely to be NDAB through LC-MS analysis (Fig. 3). In the no-starch microcosm (S0.0), MNX and MEDINA/NDAB were accumulated throughout the incubation period, and only a small amount of MNX was further transformed to DNX or TNX (Fig. 4A). Interestingly, in the starch-amended microcosms (i.e., S2.5), MNX was completely transformed into DNX and then into TNX. The accumulated TNX was eventually reduced as the incubation time increased (Fig. 4B). All RDX degradation intermediates including TNX and MEDINA/NDAB were completely removed after 75 days of incubation in the starch-amended microcosms (data not shown). However, in the same incubation period, traces of MNX were still detected in the no-starch amended microcosms (data not shown). The results indicate that the degree of RDX detoxification was significantly improved by the addition of starch.

\section{Anaysis of Microbial Community}

MiSeq sequencing targeting the 16S rRNA gene revealed that Sporolactobacillus (RCS1-RCS5) and Clostridium (RCS6-RCS10) members became predominant in all RDX-degrading microcosms regardless of starch addition.
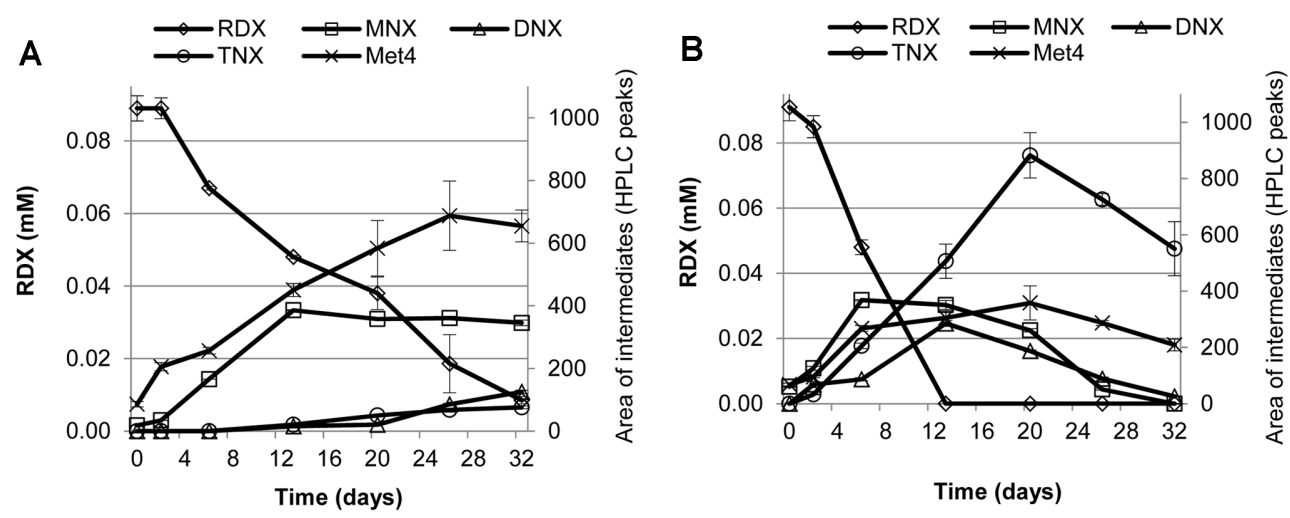

Fig. 4. Time-course changes in anaerobic RDX degradation intermediates in SO.0, the microcosm with RDX in the absence of starch $(\mathrm{A})$ and $S 2.5$, the microcosm with RDX in the presence of $2.5 \mathrm{~g} / \mathrm{lof}$ starch $(\mathrm{B})$ in the $3^{\text {rd }}$ enrichment experiments. Each error bar represents one standard deviation of three replicates. [Met4, metabolite 4 (suspected to be MEDINA or NDAB)]. 
Table 2. Relative abundances of the major genus groups (\%) that were detected in this study.

\begin{tabular}{|c|c|c|c|c|c|c|c|}
\hline OTU ID & Accession number & Phylum/Class & Genera & Initial $^{1}$ & S0.0 $0^{2}$ & $\mathrm{~S} 2.5^{3}$ & S5. $0^{4}$ \\
\hline RCS1-RCS5 & KR779830-KR779834 & Firmicutes/ Bacilli & Sporolactobacillus & 0.01 & 31.6 & 49.8 & 46.2 \\
\hline RCS6-RCS10 & KR779835-KR779839 & Firmicutes/ Clostridia & Clostridium & 0.02 & 48.2 & 42.6 & 38.4 \\
\hline RCS11-RCS12 & KR779840-KR779841 & Firmicutes/ Bacilli & Paenibacillus & 0.04 & 11.8 & 2.71 & 2.04 \\
\hline RCS13-RCS14 & KR779842-KR779843 & Proteobacteria/ Gamma & Pseudomonas & 0.14 & 0.14 & 0.06 & 2.14 \\
\hline RCS15-RCS16 & KR779844-KR779845 & Firmicutes/ Negativicutes & Sporotaelea & 0.00 & 0.01 & 0.01 & 1.13 \\
\hline
\end{tabular}

${ }^{1}$ Initial: Soil initially used for the 1 st enrichment

${ }^{2}$ S0.0: Microcosm with RDX in the absence of starch

${ }^{3} \mathrm{~S} 2.5$ : Microcosm with RDX in the presence of $2.5 \mathrm{~g} / \mathrm{l}$ starch

${ }^{4} \mathrm{~S} 5.0$ : Microcosm with RDX in the presence of $5.0 \mathrm{~g} / \mathrm{l} \mathrm{starch}$

In the S2.5 microcosm that exhibited the greatest RDX degradation rate, Sporolactobacillus was the predominant genus group ( $49.8 \%$ of total), followed by Clostridium ( $42.6 \%$ of total) (Table 2). Similar results were observed in S5.0 in which the relative abundances of Sporolactobacillus and Clostridium were $46.2 \%$ and $38.4 \%$, respectively. In the S0.0 microcosm, Clostridium was dominant ( $48.2 \%$ of the total), followed by Sporolactobacillus and Paenibacillus (RCS11-RCS12) (31.6\% and $11.8 \%$ of the total, respectively). The Sporolactobacillus and Clostridium populations may have been stimulated by RDX alone, and their stimulation was enhanced by the addition of starch. In the case

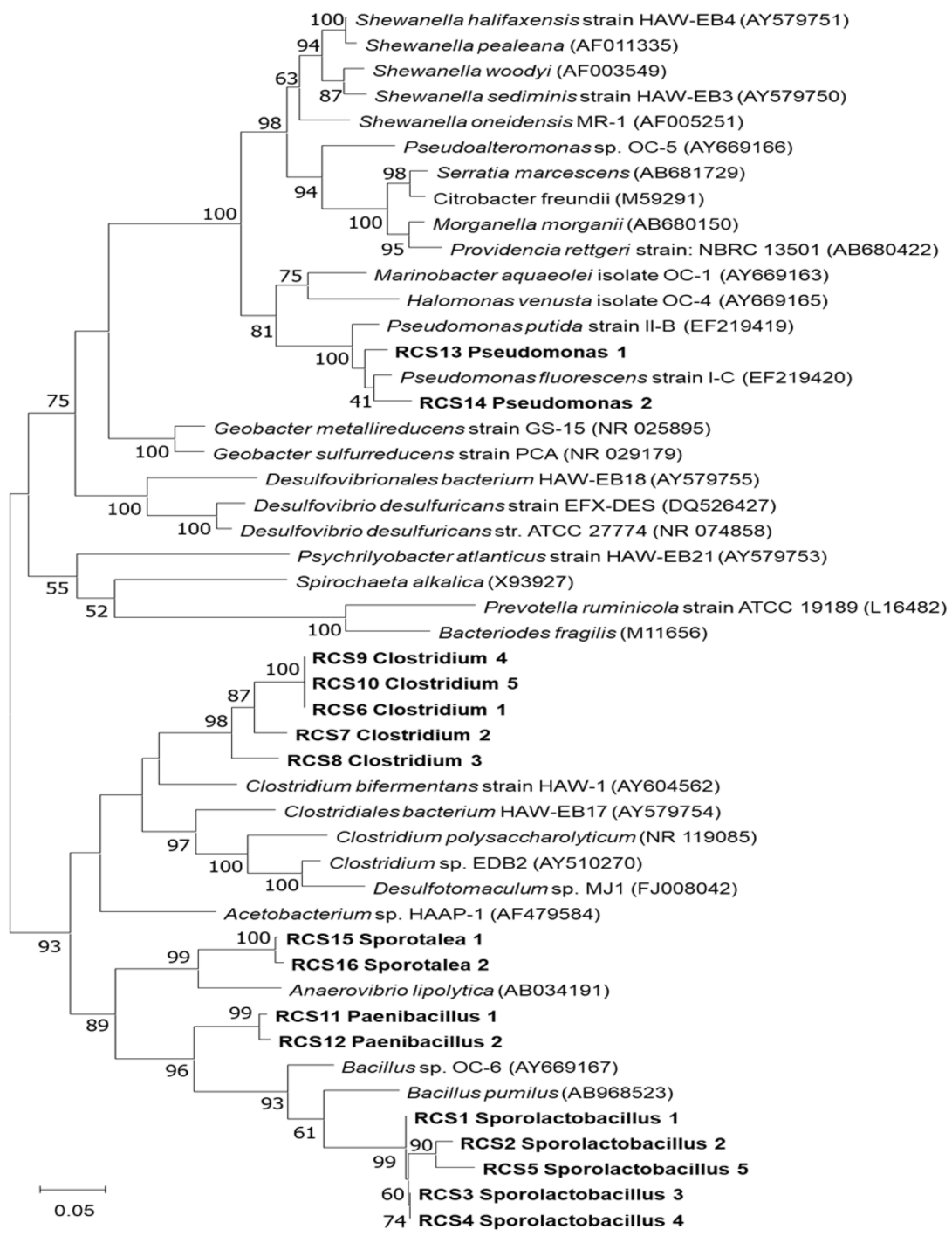

Fig. 5. Phylogenetic tree illustrating the distribution of the 16S rRNA sequences (the average size of the aligned and trimmed sequences was $470 \mathrm{bp}$ ), which were obtained by MiSeq sequencing (RCS1-RCS16), and their relationship with known anaerobic RDX-degrading bacterial isolates. The numbers beside the nodes indicate the bootstrap values from the bootstrapping test (1,000 replicates). The scale bar represents $16 \mathrm{~S}$ rRNA sequence divergence. 
of Paenibacillus, its growth-associated RDX degradation may have been stimulated by RDX alone, but their relative abundance was reduced in the presence of starch (Table 2).

A phylogenetic analysis was carried out to compare the $16 \mathrm{~S}$ rRNA gene sequences of the bacterial populations stimulated by RDX with those of previously known RDX-degrading bacteria (Fig. 5). The 16S rRNA sequences of the Sporolactobacillus (RCS1-RCS5), Clostridium (RCS6-RCS10) and Paenibacillus (RCS11-RCS12) members, the relative abundances of which significantly increased during the enrichment with RDX, were found to be phylogenetically distant from the known anaerobic RDX-degrading bacteria (more than $5 \%$ dissimilarity). The results suggested that some members of Sporolactobacillus (RCS1-RCS5), Clostridium (RCS6-RCS10) and Paenibacillus (RCS11-RCS12) may be novel anaerobic RDX-degrading bacteria. However, future studies will confirm the novelty of these members.

\section{Discussion}

The present work sought to use the co-addition of RDX and starch to develop anaerobic bacterial consortia for RDX detoxification. Furthermore, the effects of the starch addition on the rates and intermediate products of anaerobic RDX degradation and on the microbial community attributes were explored. An anaerobic RDXdetoxifying bacterial consortium was successfully enriched by the co-addition of RDX and starch, and this mixture exhibited a greater specific degradation rate than those for previously reported anaerobic RDXdegrading bacterial isolates (Table 1) [24, 27, 44-46]. To the best of our knowledge, this is first study reporting the involvement of the members of three genera including Sporolactobacillus, Clostridium and Paenibacillus together in anaerobic RDX degradation.

In this study, the sequential reduction of the nitro groups of RDX and the formation of its nitroso-derivatives by IK consortium may indicate the involvement of a nitro-reduction pathway in the observed degradation [24, 45]. However, the accumulation of nitroso-derivatives of RDX, particularly MNX is problematic because MNX is known to be the most toxic nitroso-derivatives of RDX [the order of toxicity: MNX > TNX > DNX > RDX] [11, 47]. Interestingly, MNX, the toxic RDX degradation intermediate, was significantly reduced by the addition of starch, showing improved RDX detoxification by the addition of starch. Furthermore, the formation of MEDINA or NDAB may be an indication of the ring cleavage of the nitroso-derivative intermediates [48]. The ring cleavage is considered an important step leading to the more complete degradation or mineralization.

The improvement in RDX detoxification by starch addition may be attributable to the stimulated growth of Sporolactobacillus in the microcosm. Because a significant stimulation of its growth (by the co-addition of RDX and starch) (Table 2) was positively correlated with the enhanced degradation of RDX and its nitroso-derivatives (Fig. 4). These possibilities are further supported by the literature reports that Sporolactobacillus terrae DSM 11697 [49] and S. laevolacticus DSM 442 [50] contain a variety of toxicant degrading enzymes, such as nitroreductases (WP_028982639, WP_023508470), NADPH oxidoreductases (WP_028978040, WP_031263679), dehydrogenases (WP_028983213, WP_023510728), and cytochrome C (WP_037562652, WP_031264216), which are enzymes that potentially degrade RDX and its nitroso-derivatives [11,51-52]. These findings indicate that the RDX detoxification in the anaerobic consortium may have been improved, probably via nitroreductases [51] and dehydrogenases [53] pathways, and these improvements were mainly in the starch-RDX stimulated potential RDX degraders. This present study together with our previous study demonstrated that the addition of starch enhanced the detoxification of RDX into non-toxic or less-toxic degradation products under anaerobic conditions as well as aerobic conditions [34]. Moreover, a significant amount of RDX was degraded in the nostarch live microcosms, suggesting the possible roles of RDX itself as an inducing agent for RDX degradation and a substrate for microbial growth [54]. However, for the validity of this possibility (utilization of RDX as a substrate) further stable isotope probing (SIP) experiments on ${ }^{15} \mathrm{~N}$-labeled RDX are required.

The potential RDX degraders that were dominant in the RDX-degrading consortium were found to belong to Sporolactobacillus, Clostridium, and Paenibacillus, which are facultative anaerobic, gram-positive, endosporeforming bacteria [55-57]. Clostridium is a well-known anaerobic RDX degrader [8, 27, 58, 59] and is known to carry dehydrogenases $[58,60]$ and diaphorases $[59,61]$ that are involved in RDX degradation. There are several reports on the involvement of Sporolactobacillus and Paenibacillus in anaerobic degradation of octahydro-1,3,5,7tetranitro-1,3,5,7-tetrazocine (HMX) [47, 62]. However, there has been only few reports regarding the involvement of Sporolactobacillus and Paenibacillus in anaerobic RDX degradation [63].

In short, an anaerobic bacterial consortium (IK) that can biodegrade RDX was successfully developed through sub-culture techniques with the co-addition of RDX and starch. The developed bacterial consortium was able to biotransform RDX into MNX, DNX and TNX as well as NDAB/MEDINA probably via a ring cleavage with relatively higher degradation rates. Furthermore, the detoxification of RDX by the developed anaerobic consortium was improved by the addition of starch. Taken together with our previous study of starch-enhanced aerobic RDX detoxification, the findings of this study suggest that, regardless of oxygen conditions, the addition of starch could be an effective way to stimulate explosive biodegradation for improving explosive detoxification.

\section{Acknowledgments}

This study was supported by the National Research Foundation of Korea (NRF) grant funded by the Korea government (MSIP) (No. 2011-0030040).

\section{Conflict of Interests}

The authors have no financial conflicts of interest to declare. 


\section{References}

1. Smith RW, Vlahos P, Tobias C, Ballentine M, Ariyarathna T, Cooper C. 2013. Removal rates of dissolved munitions compounds in seawater. Chemosphere 92: 898-904.

2. Andeer P, Stahl DA, Lillis L, Strand SE. 2013. Identification of microbial populations assimilating nitrogen from RDX in munitions contaminated military training range soils by high sensitivity stable isotope probing. Environ. Sci. Technol. 47: 10356-10363.

3. Arbeli Z, Garcia-Bonilla E, Pardo C, Hidalgo K, Velásquez T, Peña L, et al. 2016. Persistence of pentolite (PETN and TNT) in soil microcosms and microbial enrichment cultures. Environ. Sci. Pollut. Res. 23: 9144-9155.

4. Payne ZM, Lamichhane KM, Babcock Jr RW, Turnbull SJ. 2013. Pilot-scale in situ bioremediation of HMX and RDX in soil pore water in Hawaii. Environ. Sci. Process Impacts 15: 2023-2029.

5. Jayamani I, Cupples AM. 2015. Stable isotope probing reveals the importance of Comamonas and Pseudomonadaceae in RDX degradation in samples from a Navy detonation site. Environ. Sci. Pollut. Res. 22: 10340-10350.

6. Wilson FP, Cupples AM. 2016. Microbial community characterization and functional gene quantification in RDX-degrading microcosms derived from sediment and groundwater at two naval sites. Appl. Microbiol. Biotechnol. 100: 7297-7309.

7. ATSDR. 2010. Agency for Toxic Substances and Disease Registry. Available from http://www.atsdr.cdc.gov. Accessed Oct.12, 2019.

8. Eaton HL, De Lorme M, Chaney RL, Craig AM. 2011. Ovine ruminal microbes are capable of biotransforming hexahydro-1,3,5trinitro-1,3,5-triazine (RDX). Microb. Ecol. 62: 274-286.

9. Schoenmuth B, Mueller JO, Scharnhorst T, Schenke D, Büttner C, Pestemer W. 2014. Elevated root retention of hexahydro-1,3,5trinitro-1,3,5-triazine (RDX) in coniferous trees. Environ. Sci. Pollut. Res. 21: 3733-3743.

10. Halasz A, Hawari J. 2011. Degradation Routes of RDX in various redox systems. ACS Symp. Ser. 1071: 441-462.

11. Khan MI, Lee J, Park J. 2012. Microbial degradation and toxicity of hexahydro-1,3,5-trinitro-1,3,5-triazine. J. Microbiol. Biotechnol. 22: $1311-1323$.

12. Coleman NV, Nelson DR, Duxbury T. 1998. Aerobic biodegradation of hexahydro-1,3,5-trinitro-1,3,5-triazine (RDX) as a nitrogen source by a Rhodococcus sp., strain DN22. Soil Biol. Biochem. 30: 1159-1167.

13. Seth-Smith HM, Rosser SJ, Basran A, Travis ER, Dabbs ER, Nicklin S, et al. 2002. Cloning, sequencing, and characterization of the hexahydro-1,3,5-trinitro-1,3,5-triazine degradation gene cluster from Rhodococcus rhodochrous. Appl. Environ. Microbiol. 68: 47644771.

14. Thompson KT, Crocker FH, Fredrickson HL. 2005. Mineralization of the cyclic nitramine explosive hexahydro-1,3,5-trinitro-1,3,5triazine by Gordonia and Williamsia spp. Appl. Environ. Microbiol. 71: 8265-8272.

15. Nejidat A, Kafka L, Tekoah Y, Ronen Z. 2008. Effect of organic and inorganic nitrogenous compounds on RDX degradation and cytochrome P-450 expression in Rhodococcus strain YH1. Biodegradation 19: 313-320.

16. Crocker FH, Indest KJ, Jung CM, Hancock DE, Fuller ME, Hatzinger PB, et al. 2015. Evaluation of microbial transport during aerobic bioaugmentation of an RDX-contaminated aquifer. Biodegradation 26: 443-451.

17. Fuller ME, Hatzinger PB, Condee CW, Andaya C, Vainberg S, Michalsen MM, et al. 2015. Laboratory evaluation of bioaugmentation for aerobic treatment of RDX in groundwater. Biodegradation 26: 77-89.

18. Fuller ME, Hatzinger PB, Condee CW, Andaya C, Rezes R, Michalsen MM, et al. 2017. RDX degradation in bioaugmented model aquifer columns under aerobic and low oxygen conditions. Appl. Microbiol. Biotechnol. 101: 5557-5567.

19. Lee BU, Choi MS, Kim DM, Oh KH. 2017. Genome Shuffling of Stenotrophomonas maltophilia OK-5 for improving the degradation of explosive RDX (hexahydro-1,3,5-trinitro-1,3,5-triazine). Curr. Microbiol. 74: 268-276.

20. McCormick NG, Cornell JH, Kaplan AM. 1981. Biodegradation of hexahydro- 1,3,5-trinitro- 1,3,5-triazine. Appl. Environ. Microbial. 42: 817-823.

21. Boopathy R, Kulpa CF, Manning J. 1998. Anaerobic biodegradation of explosives and related compounds by sulfate-reducing and methanogenic bacteria: a review. Bioresour. Technol. 63: 81-89.

22. Speitel GE, Engels TL, McKinney DC. 2001. Biodegradation of RDX in unsaturated soil. Bioremed. J. 5: 1-11.

23. Morley MC, Shammas SN, Speitel GE. 2002. Biodegradation of RDX and HMX mixtures: Batch screening experiments and sequencing batch reactors. Environ. Eng. Sci. 19: 237-250.

24. Zhao JS, Halasz A, Paquet L, Beaulieu C, Hawari J. 2002. Biodegradation of hexahydro-1,3,5-trinitro- 1,3,5-triazine and its mononitroso derivative hexahydro-1-nitroso-3,5-dinitro- 1,3,5-triazine by Klebsiella pneumoniae strain SCZ-1 isolated from an anaerobic sludge. Appl. Environ. Microbiol. 68: 5336-5341.

25. Adrian NR, Arnett CM. 2007. Anaerobic biotransformation of explosives in aquifer slurries amended with ethanol and propylene glycol. Chemosphere 66: 1849-1856.

26. Arnett C, Adrian NR. 2009. Cosubstrate independent mineralization of hexahydro-1,3,5-trinitro-1,3,5- triazine (RDX) by a Desulfovibrio species under anaerobic conditions. Biodegradation 20: 15-26.

27. Bhushan B, Halasz A, Thiboutot S, Ampleman G, Hawari J. 2004. Chemotaxis-mediated biodegradation of cyclic nitramine explosives RDX, HMX, and CL-20 by Clostridium sp. EDB2. Biochem. Biophys. Res. Commun. 316: 816-821.

28. Waisner S, Hansen L, Fredrickson H, Nestler C, Zappi M, Banerji S, et al. 2002. Biodegradation of RDX within soil-water slurries using a combination of differing redox incubation conditions. J. Hazard. Mater. 95: 91-106.

29. Eaton HL, Duringer JM, Murty LD, Craig AM. 2013. Anaerobic bioremediation of RDX by ovine whole rumen fluid and pure culture isolates. Appl. Microbiol. Biotechnol. 97: 3699-3710.

30. Fuller M, Steffan RJ. 2009. Transformation of RDX and other energetic compounds by xenobiotic reductases XenA and XenB. Appl. Microbiol. Biotechnol. 84: 535-544.

31. Semenov AM, van Bruggen AHC, Zelenev VV. 1999. Moving waves of bacterial populations and total organic carbon along roots of wheat. Microb. Ecol. 37: 116-128.

32. Liu YJ, Liu SJ, Drake HL, Horn MA. 2013. Consumers of 4-chloro-2-methylphenoxyacetic acid from agricultural soil and drilosphere harbor cadA, r/sdpA, and tfdA-like gene encoding oxygenases. FEMS Microbiol. Ecol. 86: 114-129.

33. Lamichhane KM, Babcock Jr RW, Turnbull SJ, Schenck S. 2012. Molasses enhanced phyto and bioremediation treatability study of explosives contaminated Hawaiian soils. J. Hazard. Mater. 243: 334-339.

34. Khan MI, Yang J, Yoo B, Park J. 2015. Improved RDX detoxification with starch addition using a novel nitrogen-fixing aerobic microbial consortium from soil contaminated with explosives. J. Hazard. Mater. 287: 243-251

35. Kwon MJ, Finneran KT. 2006. Microbially mediated biodegradation of hexahydro-1,3,5-trinitro-1,3,5- triazine by extracellular electron shuttling compounds. Appl. Environ. Microbiol. 72: 5933-5941.

36. Ariyarathna T, Vlahos P, Smith RW, Fallis S, Groshens T, Tobias C. 2017. Biodegradation and mineralization of isotopically labeled TNT and RDX in anaerobic marine sediments. Environ. Toxicol. Chem. 36: 1170-1180.

37. EPA, U.S. 1994. Nitroaromatics and nitramines by HPLC. Second update SW-846 method 8330. Office of Solid Waste and Emergency Response, Washington, D.C., USA.

38. Sagi-Ben Moshe S, Dahan O, Weisbrod N, Bernstein A, Adar E, Ronen Z. 2012. Biodegradation of explosives mixture in soil under different water-content conditions. J. Hazard. Mater. 203-204: 333-340. 
39. George D, Mallery P. 2009. SPSS for Windows Step by Step: A Simple Guide and Reference, 16.0 Update, $9^{\text {th }}$ Ed. Allyn \& Bacon, Boston, England.

40. Klindworth A, Pruesse E, Schweer T, Peplies J, Quast C, Horn M, et al. 2013. Evaluation of general 16S ribosomal RNA gene PCR primers for classical and next-generation sequencing-based diversity studies. Nucleic Acids Res. 41: e1.

41. Yoo K, Yoo H, Lee JM, Shukla SK, Park J. 2018. Classification and regression tree approach for prediction of potential hazards of urban airborne bacteria during Asian dust events. Sci. Rep. 8: 11823.

42. Kozich JJ, Westcott SL, Baxter NT, Highlander SK, Schloss PD. 2013. Development of a dual-index sequencing strategy and curation pipeline for analyzing amplicon sequence data on the MiSeq Illumina sequencing platform. Appl. Environ. Microbiol. 79: $5112-5120$.

43. Edgar RC. 2004. MUSCLE: multiple sequence alignment with high accuracy and high throughput. Nucleic Acids Res. 32: $1792-1797$.

44. Zhao JS, Paquet L, Halasz A, Hawari J. 2003. Metabolism of hexahydro-1,3,5-trinitro-1,3,5-triazine through initial reduction to hexahydro-1-nitroso-3,5-dinitro-1,3,5-triazine followed by denitration in Clostridium bifermentans HAW-1. Appl. Microbiol. Biotechnol. 63: 187-193.

45. Adrian NR, Arnett CM. 2004. Anaerobic biodegradation of hexahydro-1,3,5-trinitro-1,3,5-triazine (RDX) by Acetobacterium malicum strain HAAP-1 isolated from a methanogenic mixed culture. Curr. Microbiol. 48: 332-340.

46. Zhao JS, Manno D, Hawari J. 2008. Regulation of hexahydro-1,3,5-trinitro-1,3,5-triazine (RDX) metabolism in Shewanella halifaxensis HAW-EB4 by terminal electron acceptor and involvement of c-type cytochrome. Microbiology 154: 1026-1037.

47. Meyer SA, Marchand AJ, Hight JL, Roberts GH, Escalon LB, Inouye LS, et al. 2005. Up-and-down procedure (UDP) determinations of acute oral toxicity of nitroso degradation products of hexahydro-1,3,5-trinitro-1,3,5-triazine (RDX). J. Appl. Toxicol. 25: 427-434.

48. Hawari J, Halasz A, Sheremata T, Beaudet S, Groom C, Paquet L, et al. 2000. Characterization of metabolites during biodegradation of hexahydro-1,3,5-trinitro-1,3,5-triazine (RDX) with municipal anaerobic sludge. Appl. Environ. Microbiol. 66: 2652-2657.

49. Huang K, Ni J, Xu K, Tang H, Tao F, Xu P. 2014. Genome sequence of Sporolactobacillus terrae DSM 11697, the type strain of the species. Genome Announc. 2: e00465-14.

50. Wang H, Wang L, Ju J, Yu B, Ma Y. 2013. Genome sequence of Sporolactobacillus laevolacticus DSM442, an efficient polymer-grade dlactate producer from agricultural waste cottonseed as a nitrogen source. Genome Announc. 1: e01100-13.

51. Kitts CL, Green CE, Otley RA, Alvarez MA, Unkefer PJ. 2000. Type I nitroreductases in soil enterobacteria reduce TNT (2,4,6,trinitrotoluene) and RDX (hexahydro-1,3,5-trinitro-1,3,5-triazine). Can. J. Microbiol. 46: 278-282.

52. Perreault NN, Crocker FH, Indest KJ, Hawari J. 2012. Involvement of cytochrome c CymA in the anaerobic metabolism of RDX by Shewanella oneidensis MR-1. Can. J. Microbiol. 58: 124-131.

53. Andeer P, Stahl DA, Bruce NC, Strand SE. 2009. Lateral transfer of genes for hexahydro-1,3,5-trinitro -1,3,5-triazine (RDX) degradation. Appl. Environ. Microbiol. 75: 3258-3262.

54. Adrian NR, Arnett CM. 2006. Hexahydro-1,3,5-trinitro-1,3,5-triazine (RDX) serves as a carbon and energy source for a mixed culture under anaerobic conditions. Curr. Microbiol. 53: 129-134.

55. Iida K, Ueda Y, Kawamura Y, Ezaki T, Takade A, Yoshida S, et al. 2005. Paenibacillus motobuensis sp. nov., isolated from a composting machine utilizing soil from Motobu-town, Okinawa, Japan. Int. J. Syst. Evol. Microbiol. 55: 1811-1816.

56. Song L, Dong X. 2008. Clostridium amylolyticum sp. nov., isolated from $\mathrm{H}_{2}$-producing UASB granules. Int. J. Syst. Evol. Microbiol. 58: 2132-2135.

57. Yu B, Su F, Wang L, Xu K, Zhao B, Xu P. 2011. Draft genome sequence of Sporolactobacillus inulinus strain CASD, an efficient D-lactic acid-producing bacterium with high-concentration lactate tolerance capability. J. Bacteriol. 193: 5864-5865.

58. Kwon MJ, Wei N, Millerick K, Popovic J, Finneran K. 2014. Clostridium geopurificans strain MJ1 sp. nov., a strictly anaerobic bacterium that grows via fermentation and reduces the cyclic nitramine explosive hexahydro-1,3,5-trinitro-1,3,5-triazine (RDX). Curr. Microbiol. 68: 743-750.

59. Li RW, Giarrizzo JG, Wu S, Li W, Duringer JM, Craig AM. 2014. Metagenomic insights into the RDX-degrading potential of the ovine rumen microbiome. PLoS One 9: e110505.

60. Bhushan B, Halasz A, Hawari J. 2005. Biotransformation of CL-20 by a dehydrogenase enzyme from Clostridium sp. EDB2. Appl. Microbiol. Biotechnol. 69: 448-455.

61. Bhushan B, Halasz A, Spain JC, Hawari J. 2002. Diaphorase catalyzed biotransformation of RDX via N-denitration mechanism. Biochem. Biophys. Res. Commun. 296: 779-784.

62. Zhao JS, Manno D, Hawari J. 2007. Abundance and diversity of octahydro-1,3,5,7-tetranitro-1,3,5,7-tetrazocine (HMX) metabolizing bacteria in UXO-contaminated marine sediments. FEMS Microbiol. Ecol. 59: 706-717.

63. Fuller ME, McClay K., Higham M, Hatzinger PB, Steffan RJ. 2010. Hexahydro-1,3,5-trinitro-1,3,5-triazine (RDX) bioremediation in groundwater: Are known RDX-degrading bacteria the dominant players? Bioremediat. J. 14: 121-134. 